\title{
Mechanical Properties of Glass Fiber Reinforced Concrete (GFRC)
}

\author{
${ }^{+}$K.I.M.Ibrahim \\ Construction Engineering Dept. , College of Engineering at Qunfudha ,Umm-Al-Qura University- KSA on \\ Sabbatical leave from higher Institute of Engineering and Technology of Kafr-EL-Shiekh - Egypt
}

\begin{abstract}
Concrete is most widely used construction material in the world. Fiber reinforced concrete (FRC) is a concrete in which small and discontinuous fibers are dispersed uniformly. The fibers used in FRC may be of different materials like steel, carbon, glass, aramid, asbestos, polypropylene, etc. The addition of these fibers into concrete mass can dramatically increase the compressive strength, tensile strength, flexural strength and impact strength of concrete. FRC has found many applications in civil engineering field. Based on the laboratory experiment on fiber reinforced concrete $(F R C)$, cube, cylinders and beams specimens have been designed with glass fiber reinforced concrete (GFRC) containing glass fibers of $0 \%, 0.1 \%, 0.3 \%$ and $0.5 \%$ volume fraction. Comparing the results of GFRC with plain concrete, this paper validated the positive effect of glass fibers with percentage increase in compression, splitting and flexure improvement of specimens at 7 and 28 days.
\end{abstract}

Keywords: Compressive Strength, Fiber Reinforced Concrete, Glass Fibers, Split Tensile Strength and flexural strength.

\section{Introduction}

Cement concrete is characterized by brittle failure, the nearly complete loss of loading capacity, once failure is initiated. This characteristic which limits the application of the material can be overcome by the inclusion of a small amount of short randomly distributed fibers (steel, glass, synthetic and natural) and can be practiced among others that remedy weaknesses of concrete, such as low growth resistance, high shrinkage cracking, low durability, etc [1].

The strength and durability of concrete can be changed by making appropriate changes in its ingredients like cemetitious material, aggregate and water and by adding some special ingredients [2]. The presence of micro cracks at the mortar-aggregate interface is responsible for the inherent weakness of plain concrete. The weakness can be removed by inclusion of fibers in the mix [3]. Different types of fibers, such as those used in traditional composite materials have been introduced into the concrete mixture to increase its toughness, or ability to resist crack growth. The fibers help to transfer loads at the internal micro cracks. Such a concrete is called fiber-reinforced concrete (FRC). Thus fiber-reinforced concrete is a composite material essentially consisting of conventional concrete or mortar reinforced by fine fibers [4]. The fibers interlock and entangle around aggregate particles and considerably reduce the workability, while the mix becomes more cohesive and less prone to segregation. The fibers are dispersed and distributed randomly in the concrete during mixing and thus improve concrete properties in all directions. Fibers help to improve the post peak ductility performance, pre-crack tensile strength, fatigue strength, impact strength and eliminate temperature and shrinkage cracks [5].Hence, this study explores the feasibility of used of glass fibers ,aim to do parametric study on compressive strength, tensile strength and flexural strength study for a given aspect ratio and various percentages of glass fiber. Presently, a number of laboratory experiments on mechanical properties of GFRC have been done. Chandramouli et al (6) had conducted experimental investigation to study the effect of using the alkali resistance glass fibers on compressive, split tensile and flexural strength on M20, M30, M40 and M50 grades of concrete. The mechanical properties of glass fiber reinforced polyester polymer concrete were evaluated. The author observed that the modulus of rupture of polymer concrete containing 20 per cent polyester resin and about 79 per cent fine silica aggregate is about $20 \mathrm{MPa}$. The addition of about 1.5 per cent chopped glass fibers (by weight) to the material increases the modulus of rupture by about 20 per cent and the fracture toughness by about 55 per cent. Muthuswamy and Thirugnanam (7) described the experimental work on Hybrid Fiber Reinforced High Performance concrete using three types of fibers namely, steel, glass and polyester fibers of a reputed brand. Silica fume was added as a mineral admixture to partially replace the cement in concrete and a super plasticizer was used to get the desired workability. A comparison with steel fiber reinforced concrete and plain concrete showed significant improvement in the strengths of the hybrid fiber reinforced concrete due to the inclusion of both fibers and silica fume. 


\section{Materials}

Local materials were used in concrete mixes and tested according to Egyptian Standard Specification (ESS) and American Standard of Testing Materials (ASTM) . gravel as a coarse aggregate was used with maximum size $25 \mathrm{~mm}$ and particle shape was approximately round fine aggregate used in this research was natural sand and it composed mainly of siliceous material .Ordinary Portland Cement was tested to assure its compliance with ESS 373-1991.supper-plasticizer was added to keep the water cement ratio $=0.50$ with slump ranges from $7-11 \mathrm{~cm}$. glass fibers(GF) of $18 \mathrm{~mm}$ length were used.

\section{Concrete Mixes Proportion}

Table (1) : Concrete Mixes Proportion

\begin{tabular}{|l|l|l|l|l|l|l|l|}
\hline Mix No. & Cement$[\mathrm{kg}]$ & Fiber Type & Fibers content\% & Gravel $\left[\mathrm{m}^{3}\right]$ & Sand $\left[\mathrm{m}^{3}\right]$ & Water[lit.] & Superplast.[kg] \\
\hline 1 & 350 & - & - & 0.80 & 0.40 & 175 & - \\
\hline 2 & 350 & glass & 0.10 & 0.80 & 0.40 & 175 & 0.70 \\
\hline 3 & 350 & glass & 0.30 & 0.80 & 0.40 & 175 & 0.875 \\
\hline 4 & 350 & glass & 0.50 & 0.80 & 0.40 & 175 & 1.05 \\
\hline
\end{tabular}

Four mixes were used as follows, one mix without fibers as a control mix , three mixes with different contents of ( GF) to study the effect of fiber content on the compressive, tensile and flexural strengths of concrete. These mixes are identical except for the volume of percentage of fibers. For all mixes the cement content was 350 $\mathrm{kg} / \mathrm{m} 3$ and water cement ratio 0.50 by weight. Super-plasticizer per cubic meter was also used.

\section{Description of tested specimens}

24 cubes $15 \times 15 \times 15 \mathrm{~cm}, 24$ cylinders $15 \times 30 \mathrm{~cm}$ and 24 beams $10 \times 10 \times 50 \mathrm{~cm}$ were cast for compressive strength, splitting tensile strength and flexural strength .Concrete was cast vertically in the forms , and was mechanically compacted using external vibrator to ensure full compaction of concrete inside the forms

\section{$V$. Test results and discussion}

Table( 2):Results of compressive strength

\begin{tabular}{|c|c|c|}
\hline Glass fiber content \% & \multicolumn{2}{|c|}{ Compressive strength $\left(\mathrm{kg} / \mathrm{cm}^{2}\right)$} \\
\cline { 2 - 3 } & 7 days & 28 days \\
\hline 0 & $223.91($ control $)$ & $283.88($ control $)$ \\
\hline 0.1 & $249.91(+11.6 \%)$ & $305.02(+7.5 \%)$ \\
\hline 0.3 & $253.68(+13.3 \%)$ & $332.2(+17 \%)$ \\
\hline 0.5 & $258.52(+15.5 \%)$ & $347.3(+22.3 \%)$ \\
\hline
\end{tabular}

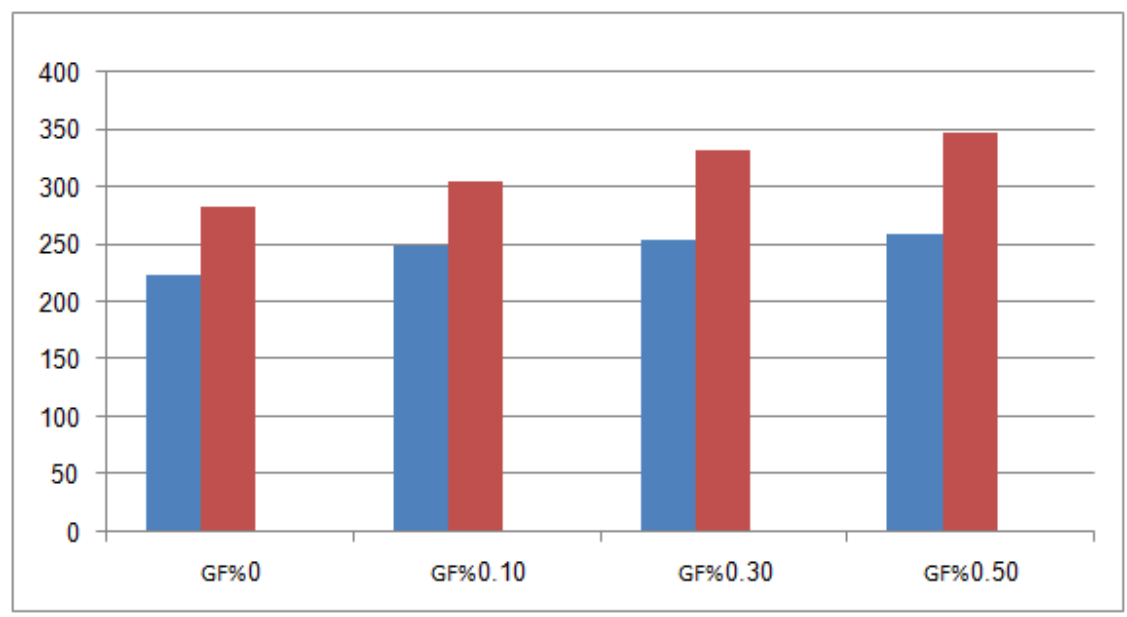

Fig.(1) : the compressive strength $(\mathrm{kg} / \mathrm{cm} 2)$ of GFRC

Table (3): Results of split tensile strength

\begin{tabular}{|c|c|c|}
\hline Glass fiber content \% & \multicolumn{2}{|c|}{ Split tensile strength $\left(\mathrm{kg} / \mathrm{cm}^{2}\right)$} \\
\cline { 2 - 3 } & 7 days & 28 days \\
\hline 0 & $15.6($ control $)$ & $19.34($ control $)$ \\
\hline 0.1 & $19.92(+27.7 \%)$ & $33.58(+27.1 \%)$ \\
\hline 0.3 & $25.3(+62.2 \%)$ & $37.62(+71.8 \%)$ \\
\hline 0.5 & $28.4(+82.1 \%)$ & $(+94.8 \%)$ \\
\hline
\end{tabular}




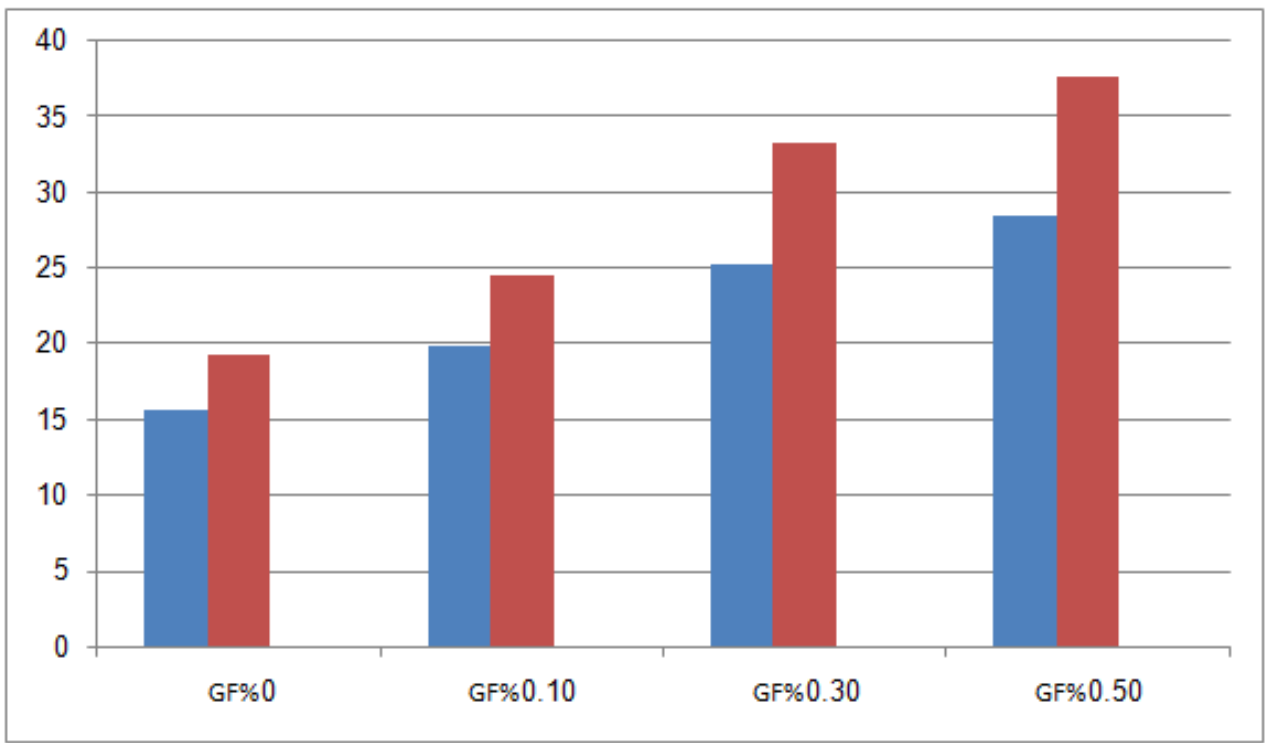

Fig.(2) : the tensile strength $(\mathrm{kg} / \mathrm{cm} 2)$ of GFRC

\begin{tabular}{|c|c|c|}
\hline Glass fiber content \% & \multicolumn{2}{|c|}{ Flexural strength $\left(\mathrm{kg} / \mathrm{cm}^{2}\right)$} \\
\cline { 2 - 3 } & 7 days & 28 days \\
\hline 0 & $34.4($ control $)$ & $43.32(\mathrm{control})$ \\
\hline 0.1 & $39.5(+14.8 \%)$ & $48.42(+11.8 \%)$ \\
\hline 0.3 & $45.87(+33.3 \%)$ & $61.16(+41.2 \%)$ \\
\hline 0.5 & $53.52(+55.6 \%)$ & $68.81(+58.8 \%)$ \\
\hline
\end{tabular}

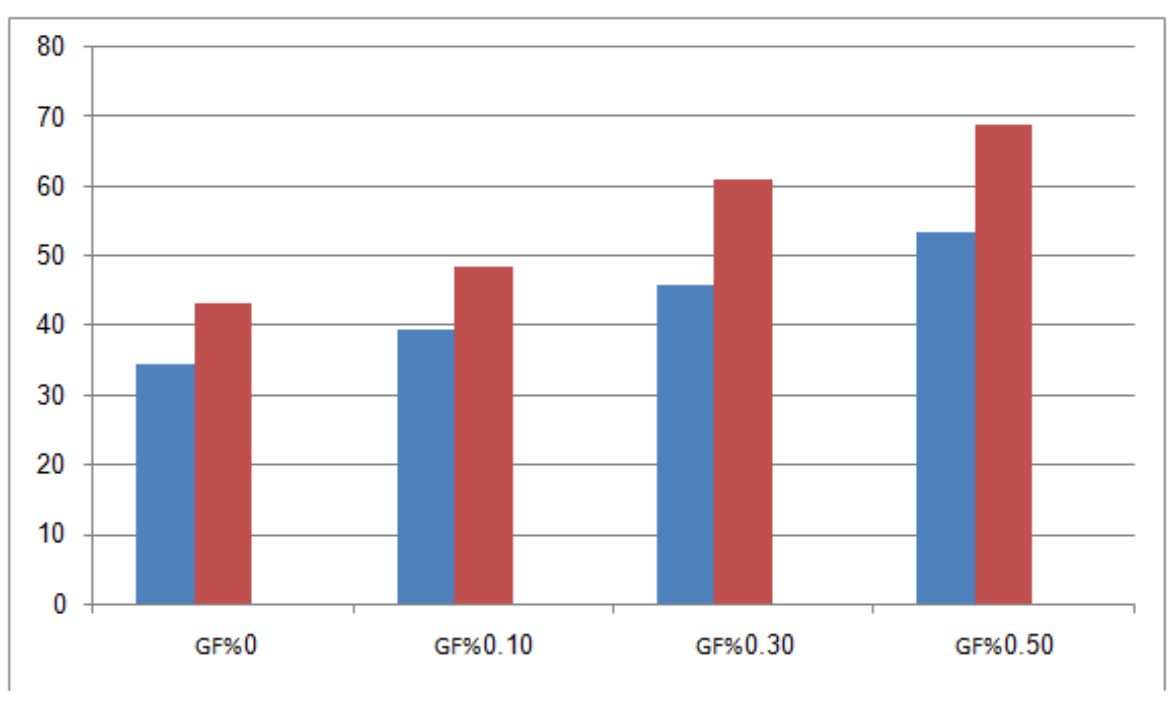

Fig.(3) : the flexural strength $(\mathrm{kg} / \mathrm{cm} 2)$ of GFRC

From Tables 2-4 it is obvious that the 28 days compressive strength of control concrete is $27 \%$ higher than that at 7 days strength and that of glass fiber reinforced concrete were $22 \%, 31 \%$ and $34 \%$ for GF content $0.1 \%, 0.3 \%$ and $0.5 \%$ respectively. the 28 days compressive strength of GFRC increases with about $7 \%, 17 \%$ and $22 \%$ for GF content $0.1 \%, 0.3 \%$ and $0.5 \%$ respectively with comparison to plain concrete. Therefore reinforcing with glass fiber contributes immensely in enhancing the compressive strength of concrete. Similarly, the split tensile strength of concrete without fiber is $24 \%$ higher than that at 28 days strength when compared to 7 days strength. The 28 days split tensile strength of glass fiber reinforced concrete was about $27 \%, 72 \%$ and $95 \%$ higher than that of normal concrete for $0.1 \%, 0.3 \%$ and $0.5 \%$ of fiber addition respectively. The 28 days flexural strength of glass fiber reinforced concrete was about $28 \%$ greater than that at 7 days. The increase in flexural strength of fiber reinforced concrete at 28 days ranges from $12 \%$ to $58 \%$. These parameters establish the supremacy of glass fiber reinforced concrete. 


\section{Conclusions}

The followings are the conclusions drawn from the study on addition of glass fiber in concrete.

1. With $0.1 \%$ addition of glass fiber, the increase in the compressive strength was about $7.5 \%$, the increase in flexural strength was about $11.8 \%$ and the increase in split tensile strength was about $27.1 \%$ over conventional concrete.

2. With $0.3 \%$ addition of glass fiber, the increase in the compressive strength was about $17 \%$, the increase in flexural strength was about $41.2 \%$ and the increase in tensile strength was about 71.8

3. With $0.5 \%$ addition of glass fiber, the increase in the compressive strength was about $22.3 \%$, the increase in flexural strength was about $58.8 \%$ and the increase in tensile strength was about $94.8 \%$.

4. Therefore reinforcing with glass fiber contributes immensely in enhancing the strength of concrete.

\section{References}

[1] V. Vairagade and K. Kene (2012) "Experimental Investigation on Hybrid Fiber Reinforced concrete", International Journal of Engineering Research and Applications, Volume 2, Issue 3, PP. 1037-1041.

[2] V. Vairagade, K. Kene and N. Deshpande (2012) "Investigation of Compressive and Tensile Behavior of Fibrillated Polypropylene Fibers Reinforced Concrete", International Journal of Engineering Research and Applications, Volume 2, Issue 3, PP. 1111-1115.

[3] A. Shende, A. Pande and M. Gulfam Pathan (2012) "Experimental Study on Steel Fiber Reinforced Concrete for M-40 Grade", International Refereed Journal of Engineering and Science, Volume 1, Issue 1, PP. 043-048.

[4] A. Shende and A. Pande(2011) "Comparative study on Steel Fiber Reinforced Cum Control Concrete", International Journal of Advanced Engineering Sciences and Technologies, Volume 6, Issue 1, PP. 116-120.

[5] V. Vairagade and K. Kene (2012) "Comparative Study of Steel Fiber Reinforced Over Control Concrete", International Journal of Scientific and Research Publications, Volume 2, Issue 5, PP. 1-4.

[6] Chandramouli, K, Srinivasa Rao, P, Pannirselvam, N, Seshadri Sekhar,T, and Sravana, Priyadrashini, T .P, (2010), “ Strength and durability characteristic of glass fiber concrete", International Journal of Mechanics of Solids ,Volume 5, No.1, PP. 15-26.

[7] Muthuawamy K.R. and Thirugnanam G.S,(2013), "Mechanical properties of hybrid fiber reinforced high performance concrete", Indian Concrete Journal, Volume 87, No. 4, April, PP. 50-55. 